\title{
Effects of fat replacing with eggplant puree on characteristics of chocolate spread
}

\begin{abstract}
Nowadays, the interest in searching for natural sources to fat replacer has increased to reduce obesity and the related with health risks. Chocolate spread products are the most important products of candy that are popular and more consumed, especially by children where it is a source of energy also its high nutritional value. This research aims to assess the fat replacement by eggplant puree at $25 \%$ and $75 \%$ from the total fat content and its effects on the sensory properties, texture, chemical composition, minerals content, fatty acid composition, polyphenol compound content as tannic acid and storage stability as free fatty acid (FFA), thiobarbituric acid (TBA), total plate count (TPC) and yeasts and molds count and compared by control sample. The obtained results showed that no significant difference in sensory properties between all the products, while Chocolate spread containing $25 \%$ eggplant puree substituted were the highest in most Texture properties, the chemical composition was affected by the increasing of eggplant puree, that noted an increasing moisture, ash, dietary fiber and minerals contents while the crude ether extract and energy values were significantly $(\mathrm{p}<0.05)$ decreased. The fatty acid profile for the three products was within the permissible limit, tannic acid values were 318.92, 401.28 and 661.46 $\mathrm{mg} / 100 \mathrm{~g}$. Finally found that the FFA values which were ranged from $1.73 \%$ to $10.75 \%$, TBA values which were ranged from 2.21 to $6.87 \mathrm{mg}$ Malon-aldehyde/kg sample. The use of these fat replacements has improved all the properties of Chocolate spread except the storage stability.
\end{abstract}

Keywords: spread chocolate; eggplant puree; fat replacer; polyphenol; storage stability
Volume 8 Issue 3 - 2020

\author{
Maha IK Ali, Rehab A Mostafa, Ahmed E \\ Abdel Gawad \\ Department of Special Food and Nutrition, Food Technology \\ Research Institute, Agricultural Research Center, Egypt
}

Correspondence: Maha IK Ali, Department of special food
and nutrition, Food Technology Research Institute,Agricultural
Research Center, Giza, Egypt, E-mail mahaik82@yahoo.com

Received: October 2I, 2020 | Published: December 07, 2020

\section{Introduction}

Recently consumer requirements have changed not only to produce food to close the hunger gap but to eat healthy food to improve the physical and mental health of people and prevent the spread of food diseases. ${ }^{1}$ Fat is a major dietary component for the human body and is one of the major ingredients in our daily diet. ${ }^{2}$ Although the nutritional benefits are well known, the excessive consumption of fats, especially saturated types, was found to be associated with some health problems like obesity, cardiovascular and coronary heart diseases. ${ }^{3}$ Fats import many functional and sensory properties in food products which is help develop texture, mouth feel, odor, taste and flavor of foods. ${ }^{4}$ Chocolate is one of the most favorite foods in children and adults alike. It is a rich source of energy and characterized by rapid metabolism and suitable digestion. However, it is high in fat. Fat decrease is a major challenge for producers. ${ }^{5}$ Chocolate spread is usually made of milk powder, sugar, fat, cocoa powder and lecithin. The spread usually use in bread toasts and muffins ${ }^{6,7}$ Fat replacer play an important role in reducing fat or calories in food and are divided into three main types carbohydrate, lipid, or protein based fat replacers. ${ }^{8-10}$ lso pawpaw fruit puree, ${ }^{11}$ avocado puree,${ }^{12}$ cocoa fiber ${ }^{13}$ and apple sauce ${ }^{4}$ used as natural fat replacers. Eggplant (Solanummelongena L.) are vegetable belonging to the Solanaceae. ${ }^{14}$ also it considered to be one of the most species vegetables and the best, Because of its high content of Antioxidant, which eliminate the harmful effects of free radical..$^{15}$

Also eggplant is an excellent source of phytochemical like phenolic compound which play an important role in diseases prevention and types of cancer and chronic diseases. ${ }^{16}$ In addition, it contains minerals such as potassium, calcium, sodium and iron. ${ }^{17,18}$ Also considered as good source of dietary fiber which play important to reduce the risk of cardiovascular diseases, diabetes, obesity and certain types of cancers. ${ }^{19}$ Eggplant was chosen as the fat replacement because of its health benefits. The researchers reported that there is a opposite relationship between amount of vegetables in products and the dominance of metabolic syndrome..$^{20}$ Also they knew how eggplant good affects the cholesterol absorption whereas the eggplant have a good ability to bind the salts of bile which using in metabolism of the cholesterol. ${ }^{21}$ The objective of the present study is to evaluate the effects of fat replacing with eggplant puree on characteristics of chocolate spread.

\section{Materials and methods}

\section{Materials}

Eggplant (Solanummelongena L.), skimmed milk liquid, honey, beeswax, butter, cocoa powder, and lecithin were obtained from the local market, Alexandria, Egypt. All chemicals and reagents used in this study were of analytical grade and purchased from Sigma Co.

\section{Methods}

Preparation of eggplant puree: The eggplant free of seeds were selected, it was washed with tap water to remove any soil particle and dirt. it was peeled and Shredded into rings in a stainless steel vessel a $100 \mathrm{ml}$ water with $0.1 \%$ cetric acid was add and boiled for $8-10$ minutes at $100^{\circ} \mathrm{C}$ then left to cool at room temperature, then blended until smooth texture obtained and finally put in plastic bags in freezer. ${ }^{22}$

Preparation of chocolate spread: Chocolate spread were prepared in a straight mixed process according to the methods described by El-Hadad ${ }^{23}$ with some modifications. Initially, it is mixed $100 \mathrm{~g}$ honey, $50 \mathrm{ml}$ skimmed liquid milk and $0.25 \mathrm{~g}$ Citric acid then, the mixture was heated in water bath. $77 \mathrm{~g}$ butter, $3 \mathrm{~g}$ lecithin and $20 \mathrm{~g}$ cocoa 
powder were mixed in at low speed for 2 min using a hand blender, finally the two mixture were mixed at low speed for $30 \mathrm{~min}$, then packaged in glass jars. the butter was replaced with 25 (17.33 g) and $75 \%(57.75 \mathrm{~g})$ from eggplant puree With the same mixing steps that were followed in the control sample.

Sensory analysis: The three samples formulated in the present study were served to ten staff members of Special Food and Nutrition Research Department, Food Technology Research Institute, Egypt. The panelists were asked to judge for color, taste, odor, texture, and overall acceptability of chocolate spread according to standard hedonic rating scale from 9 (like extremely) to 1 (dislike extremely) according to Kramer \& Twigg ${ }^{24}$.

Texture profile analysis: Samples were measured by Brookfield Pro CT V1.2 Build 9. A probe TA4/1000 penetrated into each formula using speed $2 \mathrm{~mm} / \mathrm{s}$ to distance $7.5 \mathrm{~mm}$ into each sample at two cycles, the load cell was $1000 \mathrm{~g}$, test speed and return speed were 2 $\mathrm{mm} / \mathrm{s}$ and the force was recorded as gram. ${ }^{25}$

Chemical components analysis: Proximate Chemical composition including moisture, crude ether extract, crude nprotein, crude fiber and total ash. Also PH values were determined in $10 \mathrm{~g}$ of each sample which was mixed with $10 \mathrm{ml}$ distilled water. ${ }^{26}$

Minerals contents: Minerals (zinc, iron, magnesium, manganese, calcium, potassium, sodium and phosphorus) contents were determined by dry ash according to produce of the U.S. EPA ${ }^{27}$ using an Inductively coupled plasma atomic emission spectroscopy (ICPOES).

Fatty acid composition: Preparation of fatty acid methyl esters of oils extracted from chocolate spread was performed according to the procedure of Radwan et al., ${ }^{28}$, using $1 \%$ sulphuric acid in absolute methanol. The fatty acid methyl esters obtained were separated by Shimodzu gas chromatograph (GC- 4 CM- PFE) under the following conditions: column, $10 \%$ DEGS on 801100 chromosorb Q III; Detector temperature $270^{\circ} \mathrm{C}$ : flow, N2 and chart speed, $5 \mathrm{~min}$. Standard fatty acid methyl esters were used for identification. The area under each peak was measured bythe triangulation method as percentage of each fatty acid was regard to the total area.

Tannic acid content and antioxidants activity: HPLC System Agilent using to determine tannic acid in the three chocolate spread sample, in this method $10 \mathrm{mg}$ sample was dissolved in 10 $\mathrm{ml}$ of mobile phase (Methanol: Water (50:50)) and was injected in apparatus with pump LC-P-100, detector LC-UV-100 UV/VIS, detector column temperature ambient and wavelength of detection 270. The chromatographic conditions for analysis were flow rate $1 \mathrm{~mL} / \mathrm{min}$, sample volume $20 \mu \mathrm{L}$, run time $12 \mathrm{~min}$ and retention time $3.1 \mathrm{~min}$. The quantification of tannic acid was calculate using an absolute calibration curve method using standard solutions of tannic acid. ${ }^{29}$ Radical scavenging activity of chocolate spread sample was measured using the DPPH (2, 2-diphenyl-1-picrylhydrazyl) according to Brandwilliams et al. ${ }^{30}$. The determination of DPPH scavenging for chocolate spread sample using $1 \mathrm{mM}$ solution of DPPH in ethanol and also $1 \mathrm{mg} / 1 \mathrm{ml}$ extract solution in ethanol was prepared and $1.5 \mathrm{ml}$ of this solution was added to $1.5 \mathrm{ml}$ of DPPH. The absorbance was measured at $517 \mathrm{~m}$ against the corresponding blank solution which is prepared by taking $3 \mathrm{ml}$ ethanol and control O.D. was prepared by taking $3 \mathrm{ml}$ of DPPH. The assay was performed in triplicates. Percentage inhibition of free radical DPPH was calculated based on control reading by following equation.

Scavenging DPPH \% $=\left[\mathrm{Abs}_{\text {control }-} \mathrm{Abs}_{\text {sample }}\right) \times 100 / \mathrm{Asb}_{\text {control }}$

\section{Storage stability determination}

FFA and TBA values analysis: According to Poonam et al. ${ }^{31}$ with modification in extraction method of fat from choclate spread sample Folish cold extraction method using to extract fat from the samples at zero time and after 3 months of cold storage. Dissolved $5 \mathrm{~g}$ fat in 50 $\mathrm{ml}$ of hot neutralized alcohol in presence of $1.0 \mathrm{ml}$ of phenolphthalein as indicator. Titrate the hot mixture with the standard $0.1 \mathrm{~N} \mathrm{NaOH}$ solution to end point (pink color) for at least 15 seconds.

Free fatty acids (as Oleic acid), per cent by mass $=$ VX N X 28.2/

Where,

$\mathrm{V}=$ volume in $\mathrm{ml}$ of the standard sodium hydroxide solution used for titration

$\mathrm{N}=$ normality of the standard potassium/sodiumhydroxide solution,

$\mathrm{M}=$ mass in $\mathrm{g}$ of the sample taken for the test

Regarding thiobarbituric acid (TBA) value was determined for the samples at zero time and after 3 months of cold storage according to Kirk \& Sawyer ${ }^{32}$. Ten g sample were distilled with $47.5 \mathrm{ml}$ of distilled water $+2.5 \mathrm{ml}$ of $4 \mathrm{~N} \mathrm{HCl}$ for $10 \mathrm{~min}, 5 \mathrm{ml}$ of distilled sample was added to $5 \mathrm{ml}$ of TBA solution, and then heated in boiling water bath for $35 \mathrm{~min}$. After cooling, absorbance was measured at $538 \mathrm{~min}$ by using Spekol 11 Spectrophotometer. The TBA value was calculated as $\mathrm{mg}$ malonaldehyde per $\mathrm{kg}$ sample by multiplying the absorbance $\mathrm{A}$ (OD) by the factor 7.8.

Microbiological evaluation: Total plate count (TPC) was determined for the samples at zero time and after 3 months of cold storage by using pour plate method and plate count agar as medium according to ISO $8443^{33}$. For Yeasts \& moulds were determined by plating 0.05 $\mathrm{ml}$ of diluted sample on potato dextrose agar(Oxoid CM)incubated for 5 days at $25^{\circ} \mathrm{C}$, yeasts \&moulds colonies were counted separately according to $\mathrm{ICMSF}^{34}$

Statistical Analysis: All data of the present study were expressed as mean values \pm SD of variance (ANOVA) followed by using t- test (LSD) at $\mathrm{P} \leq 0.05$ being considered statistically significant using (SAS) software program..$^{35}$

\section{Results and discussion}

\section{Sensory analysis}

The sensory properties of all formulas were ranged from extremely like to very like acceptance with no significant differences in all sensory properties between the three formulas except the color in formula $25 \%$ which was recorded lowest color score between the three samples. Meanwhile the formulas with $75 \%$ eggplant puree as a partial fat replacer from the ratio of total fat had the highest score in color, taste, odor, texture and overall acceptability between the three ones as mentioned in (Table 1). Nazir \& Azad, ${ }^{36}$ stated that the lipid composition in chocolate product effects in sensory properties such as taste and mouth feel. Structure of fat especially, triglycerides in spread Chocolate which contain saturated fatty acids such stearic and palmetic and also oleic acid as monosaturated fatty acid are reasonable to its mouth feel evaluation. On the other hand, the sensory characteristics affects by the chocolate ingredients such as type of milk and cocoa type and also the manufacturing method which explain that sensory analysis of chocolate spread in this paper may differ due to the difference in the percentage of fat content, ingredients 
and the processing method. As well Hussein ${ }^{37}$ observed that there no differences between the acceptability of cakes made with vegetable puree up to $75 \%$ and control cakes. Using of vegetable puree did not accompany by an unwanted color. Whereas, the high moisture content in vegetable puree cakes were more accepted by the panelists.

Table I The sensory properties of chocolate spread formulas

\begin{tabular}{lllll}
\hline \multirow{2}{*}{ Properties } & \multicolumn{2}{l}{ Formulas } & & \\
\cline { 2 - 5 } & Control (100\%butter) & $\mathbf{2 5 \%}$ Substitution & $\mathbf{7 5 \%}$ Substitution & LSD \\
\hline Color & $8.40 \pm 0.70^{\mathrm{a}}$ & $7.70 \pm 0.95^{\mathrm{b}}$ & $8.50 \pm 0.53^{\mathrm{a}}$ & 0.68 \\
Taste & $7.90 \pm 0.74^{\mathrm{a}}$ & $7.70 \pm 0.82^{\mathrm{a}}$ & $8.10 \pm 1.20^{\mathrm{a}}$ & 0.86 \\
Odor & $8.20 \pm 0.63^{\mathrm{a}}$ & $8.20 \pm 0.63^{\mathrm{a}}$ & $8.30 \pm 0.67^{\mathrm{a}}$ & 0.59 \\
Texture & $7.90 \pm 0.88^{\mathrm{a}}$ & $7.60 \pm 0.84^{\mathrm{a}}$ & $8.10 \pm 0.99^{\mathrm{a}}$ & 0.83 \\
Overall acceptability & $8.10 \pm 0.88^{\mathrm{a}}$ & $7.70 \pm 0.82^{\mathrm{a}}$ & $8.30 \pm 0.82^{\mathrm{a}}$ & 0.77 \\
\hline
\end{tabular}

$25 \%$ eggplant puree and $75 \%$ eggplant puree from butter in chocolate spread.

*Each value of each formula is a mean of three replicates $\pm S D$.

Means followed by the same letter, in each row are not significantly different (ANOVA, LSD test $p \leq 0.05$.).

Table 2 The texture profile analysis of chocolate spread formulas

\begin{tabular}{llll}
\hline \multirow{2}{*}{ Texture profile analysis } & Formulas & & \\
\cline { 2 - 4 } & Control (1 00\%butter) & $\mathbf{2 5 \%}$ Substitution & $\mathbf{7 5 \% ~ S u b s t i t u t i o n ~}$ \\
\hline Hardness cycle I (g) & 266 & 580 & 339 \\
Hardness cycle 2 (g) & 234 & 463 & 326 \\
Adhesiveness (mJ) & 37.4 & 18.5 & 9.1 \\
Springiness length (mm) & 7.09 & 8.29 & 5.97 \\
Gumminess $(\mathrm{g})$ & 133 & 510 & 252 \\
Chewiness $(\mathrm{mJ})$ & 17.4 & 85.4 & 14.8 \\
\hline
\end{tabular}

$25 \%$ eggplant puree and $75 \%$ eggplant puree from butter in chocolate spread.

\section{Texture profile analysis}

Spread ability of chocolate spread is the most texture property affecting its acceptance. The spread ability explained as hardness which is amount of the force using to penetrate the probe of Brookfield apparatus the sample. The spread ability have an opposite correlation with hardness value. (Table 2) showed the hardness values (g) of the three experimental samples which recorded the highest hardness in cycle 1 and 2 was the sample which contain $25 \%$ eggplant puree then $75 \%$ and finally whole butter sample. The degree of adhesiveness $(\mathrm{mJ})$ was the highest in control sample then $25 \%$ and the lowest one was $75 \%$ the degree of decrease was reached to the double between each sample that may explain the distribution of emulsion particals in each sample which affecting by samples composition, mixing technique and processing method. The springiness length $(\mathrm{mm})$ was the highest in $25 \%$ followed by control and $75 \%$, respectively. The gumminess ( $\mathrm{g}$ ) and chewiness $(\mathrm{mJ})$ were the highest in substitution of $25 \%$ eggplant puree $510 \mathrm{~g}$ and $85.4 \mathrm{~mJ}$, these values in $75 \%$ sample were $252 \mathrm{~g}$ and $14.8 \mathrm{~mJ}$ and finally, the control one values were $133 \mathrm{~g}$ and $17.4 \mathrm{~mJ}$. (Figure 1) showed the deformation of samples in cycle 1 and 2 and we noticed that the deformation was the highest in $75 \%$ substitution sample and the lowest in the control one that may refer to the degree of adhesiveness in the samples.

Fat content have been imported factor that affecting in instrumental texture values in different researches, that fat coating of particles decreases attraction between them and decrease flow with decrease fat content in dark chocolate ${ }^{38}$ and that in opposite relationship in this study which the full cream sample (control) had the highest adhesiveness that may refer to the method of processing and the degree of mixing. Full et al. ${ }^{39}$ found that spread ability and hazelnut oil content were in an opposite relationship because the solid fat content was changed. In the same opposite relationship effect of solid fat content on hardness values was found in the chocolate spreads. In the current study when the ratio of fat decreased the hardness increased and spread ability decreased that due to the replacement the fat by eggplant puree which contain more fiber and carbohydrate. Hussein ${ }^{37}$ noticed that the use of vegetable puree as a fat replacer in preparing cakes a significant increase in hardness, springiness and chewiness, but to a limited extent the cohesiveness.

\section{Chemical components analysis and Minerals content}

In (Table 3) was illustrated the chemical composition of the samples, and it can noted that the moisture contents were $30.35,33.87$ and $42.53 \%$ in control, $25 \%$ and $75 \%$ egg plant puree, respectively. These ratios in the formulas which were contained the eggplant puree as a partial fat replacer of the animal fat were higher than the control sample and the increasing in moisture ratio was in direct proportion to the increase in the proportion of eggplant puree. This increasing in eggplant puree ratio in formulas was accompanied by decreasing in protein content, where the protein content was decreased to a third in the $75 \%$ eggplant puree formula $(1.27 \%)$ with marked and desirable decreased in crude ether extract reached to $8.87 \%$ compared with same content in the control formula was $34.14 \%$. That was decreased about 4 times in crude ether extract accompanied increased 
in ash, carbohydrate and crude fiber content $(3.92 \%, 40.08 \%$ and $3.33 \%$,respectively meanwhile decreased in energy value to 241.40 $\mathrm{Kcal} / 100 \mathrm{~g}$. These results agree with Hussein ${ }^{37}$ who reported the decrease in caloric values and fat in cake prepared with vegetable puree as a fat substitute.

Table 3 Chemical composition of chocolate spread formulas

\begin{tabular}{|c|c|c|c|c|}
\hline \multirow{2}{*}{ Components (\%) } & \multicolumn{4}{|l|}{ Formulas } \\
\hline & Control ( $100 \%$ butter) & $25 \%$ Substitution & 75\% Substitution & LSD \\
\hline Moisture & $30.35 \pm 1.15^{b}$ & $33.87 \pm 1.62^{\mathrm{a}}$ & $42.53 \pm 2.95^{\mathrm{a}}$ & 4.1 \\
\hline Crude protein* & $3.59 \pm 1.97^{\mathrm{a}}$ & $3.94 \pm 0.26^{\mathrm{a}}$ & $1.27 \pm 0.28^{b}$ & 2.31 \\
\hline Crude ether extract* & $34.14 \pm 2.16^{\mathrm{a}}$ & $27.17 \pm 0.34^{b}$ & $8.87 \pm 0.48^{c}$ & 2.58 \\
\hline Ash* & $3.55 \pm 0.68^{\mathrm{a}}$ & $3.68 \pm 0.34^{a}$ & $3.92 \pm 0.24^{\mathrm{a}}$ & 0.91 \\
\hline Carbohydrate* & $27.54 \pm 2.95^{\mathrm{b}}$ & $28.45 \pm 1.75^{b}$ & $40.08 \pm 2.70^{\mathrm{a}}$ & 5.03 \\
\hline Crude fiber* & $0.84 \pm 0.16^{c}$ & $2.87 \pm 0.13^{b}$ & $3.33 \pm 0.33^{\mathrm{a}}$ & 0.44 \\
\hline Energy value* (Kcal/l00g) & $420.99 \pm 8.98^{\mathrm{a}}$ & $363.3 \mathrm{I} \pm 4.72^{\mathrm{b}}$ & $24 I .40 \pm 14.27^{c}$ & 20.2 \\
\hline
\end{tabular}

$25 \%$ eggplant puree and $75 \%$ eggplant puree from butter in chocolate spread.
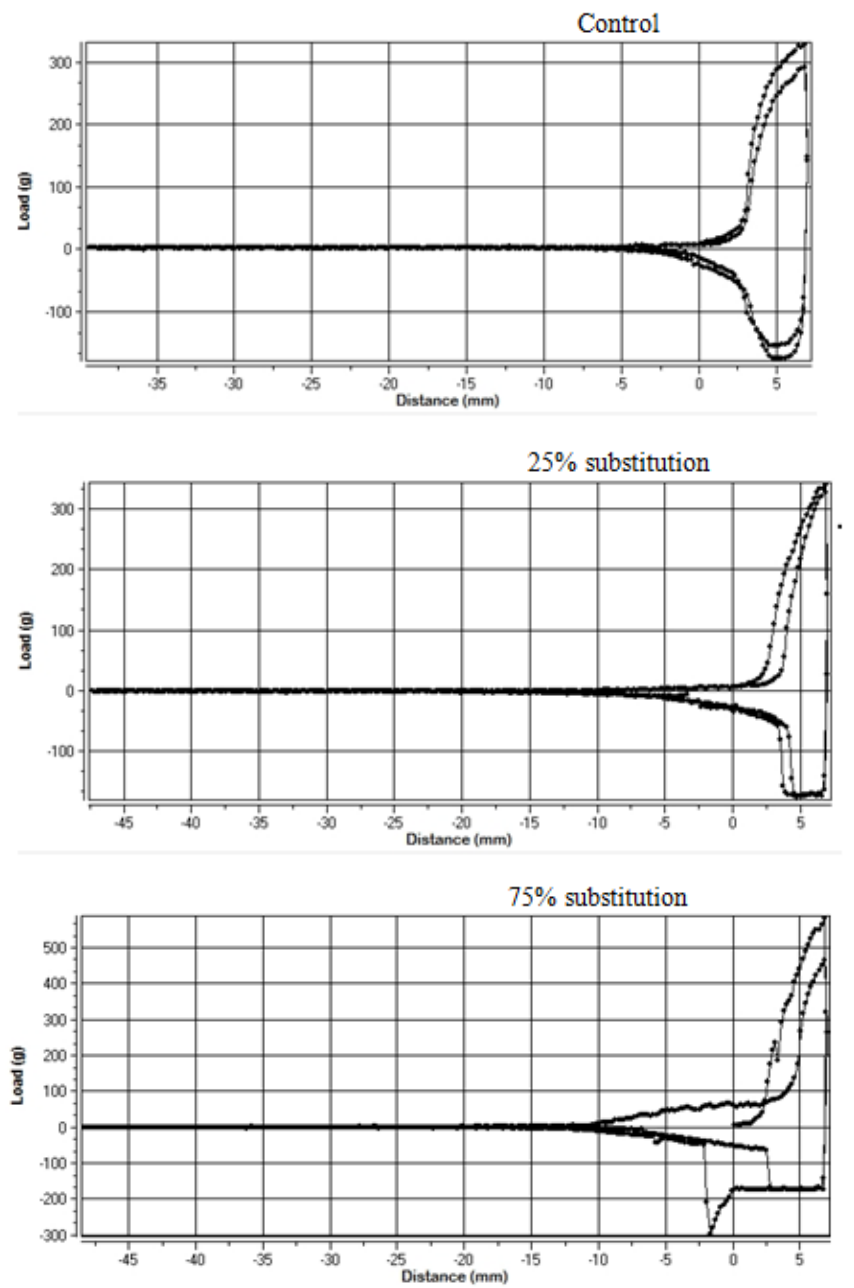

Figure I Deformation at hardness of chocolate spread formulas.

\section{Minerals content}

The minerals content was recorded in (Table 4) and observed that the third formulas which had $75 \%$ eggplant puree recorded the highest content in all investigated minerals $(\mathrm{Fe}, \mathrm{Ca}, \mathrm{K}, \mathrm{Na}, \mathrm{Zn}, \mathrm{Mg}, \mathrm{Mn}$ and P) then 25\% eggplant puree formula and at the end. The increased in calcium and phosphor contents were little more than the double (from 194.80 to $442.55 \mathrm{mg} / 100 \mathrm{~g}$ and from 267.88 to $542.10 \mathrm{mg} / 100 \mathrm{~g}$ ), also the increased in potassium content was the double ( from 1738.70 to $2552.90 \mathrm{mg} / 100 \mathrm{~g}$ ) and this increased was not equaled with the increased in sodium content which was $263.41 \mathrm{mg} / 100 \mathrm{~g}$ in control formula and it was became $392.65 \mathrm{mg} / 100 \mathrm{~g}$ in the $75 \%$ eggplant puree one. Beside there was increased in the rest minerals which near to the double. Adubofuor et al ${ }^{40}$ found a significant increase in magnesium, sodium and potassium contents accompanied by the level of substitution by partially dried ripe pawpaw pulp in rock buns and cakes prepared from the pawpaw pulp incorporated into wheat flour. The increasing in the inorganic minerals have good nutritional effects such as potassium which play important roles in the maintenance of normal glucose-tolerance and in the release of insulin from beta cells.

\section{Fatty acid composition}

(Table 5) illustrated the fatty acid profile of the three formulas of chocolate spread and this tables showed that the formulas were contained many short chain fatty acids such as caprylic (C8:0), capric( C10:0), undecylic(C 11:0) and tridecylic (C13:0) acids in small quantities on the other side, the control formula was not contained such fatty acids but it was contained other long chain saturated fatty acids in varying amounts starting such as myristic (C14:0), palmitic(C16:0), margaric(C17:0) and stearic (18:0) acids beside large amounts of linoleic(C18:1c, 42.88\%) and linolenic (C18:2c, 17.84\%) acids in cis form. The same fatty acids were found in the other two eggplants puree formulas over more some unsaturated fatty acids such as palmitoleic (C16:1) and paullinic (C20:1) acids, the last fatty acid was appeared only in $75 \%$ eggplant puree formula $(0.146 \%)$. The saturated fatty acids to unsaturated fatty acids ratios were calculated for the three formulas, they were $1: 1.55,1: 1.39$ and $1: 1.28$ for control formula which was contained 100,75 and $25 \%$ animal butter, respectively. Kara et al. ${ }^{41}$ determined the fatty acid composition in 13 samples from 10 different brands of chocolate spread in Turkey. The samples contained 14 fatty acids, these fatty acids were palmitic acid (9.82-27.19\%), oleic acid (26.27-56.05\%) and linoleic acid (10.87$52.40 \%$ ). The saturated fatty acids (SFA) of the samples ranged from 17.01 to $32.03 \%$, monounsaturated fatty acids (MUFA) ranged from 19.74 to $57.00 \%$ and polyunsaturated fatty acids (PUFA) ranged from 11.01 to $52.51 \%$. These results found the contents of the fatty acids in 
the samples correlated with legal limits. These results were relatively agreed with our ratios of saturated and polyunsaturated fatty acids for the experimental samples of chocolate spread.

\section{Tannic acid content and antioxidants activity}

As shown in (Figures $2 \& 3$ ) the tannic acid content and antioxidant activity of the three samples of chocolate spread .It was found that both value increased with increasing the ratio of eggplant puree which was a good source of polyphenols which act as antioxidants. The tannic acid contents were $318.92,401.28$ and $661.46 \mathrm{mg} / 100 \mathrm{~g}$ for control, $25 \%$ and $75 \%$ samples, respectively. That was paralleled with the antioxidant activities of the three formulas which the $75 \%$ eggplant puree formula was also the highest in its antioxidants activity
(88.22\%) then $25 \%$ eggplant puree formula $(84.75 \%)$ and finally, the lowest one was the control chocolate spread (66.59\%). Stommel \& Whitaker ${ }^{42}$ showed that eggplant is consider one of among the ten best vegetables by its ability to absorb oxygen radicals because of its high content of phenolic compounds. Flavonoids, phenolic acids and polyphenols are the main classes of dietary phytochemicals, phenolic polymers, commonly known as tannins, are compounds of high molecular weight that are divided into classes, hydrolyzable tannins and condensed tannins and they found that eggplant fruit phenolic content provide opportunities to improve eggplant quality and value and they reported that about of $64.3 \%$ to $96 \%$ of total hydroxycinnamic acids HCA was chlorogenic acid. Also, they illustrated that vegetables have antioxidant quality comparable to that of pure phenol and superior to that of antioxidant vitamin $\mathrm{A}, \mathrm{C}$ and $\mathrm{E}$.

Table 4 Minerals Content of chocolate spread formulas $(\mathrm{mg} / \mathrm{l} 00 \mathrm{~g})$ on dry weight basis

\begin{tabular}{|c|c|c|c|c|c|c|c|c|}
\hline \multirow{2}{*}{ Formulas } & \multicolumn{8}{|c|}{ Element } \\
\hline & $\mathbf{F e}$ & $\mathrm{Ca}$ & $\mathbf{K}$ & $\mathrm{Na}$ & Zn & Mg & Mn & $\mathbf{P}$ \\
\hline Control (I00\% butter) & $16 . .95$ & 194.8 & 1738.7 & 263.41 & 3.65 & $|33.5|$ & 1.54 & 267.88 \\
\hline $25 \%$ Substitution & 17.25 & 213.9 & 1750.25 & 254.1 & 3.95 & 146.33 & 1.63 & 251.28 \\
\hline $75 \%$ Substitution & 28.65 & 442.55 & 2552.9 & 392.65 & 5.77 & 226.46 & 2.65 & 542.1 \\
\hline
\end{tabular}

$25 \%$ eggplant puree and $75 \%$ eggplant puree from butter in chocolate spread.

Table 5 Fatty acids composition (\%) of chocolate spread formulas

\begin{tabular}{|c|c|c|c|c|c|c|c|}
\hline \multirow{2}{*}{$\begin{array}{l}\text { Fatty } \\
\text { acids } \\
(\%)\end{array}$} & \multicolumn{3}{|l|}{ Formulas } & \multirow{2}{*}{$\begin{array}{l}\text { Fatty acids } \\
\text { (\%) }\end{array}$} & \multicolumn{3}{|l|}{ Formulas } \\
\hline & $\begin{array}{l}\text { Control (100\% } \\
\text { butter) }\end{array}$ & $\begin{array}{l}25 \% \\
\text { Substitution }\end{array}$ & $\begin{array}{l}75 \% \\
\text { Substitution }\end{array}$ & & $\begin{array}{l}\text { Control (100\% } \\
\text { butter) }\end{array}$ & $\begin{array}{l}25 \% \\
\text { substitution }\end{array}$ & $\begin{array}{l}75 \% \\
\text { Substitution }\end{array}$ \\
\hline C8:0 & ND & 0.064 & 0.433 & $\mathrm{Cl} 6: \mathrm{I}$ & ND & 0.146 & 0.549 \\
\hline $\mathrm{ClO} 0: 0$ & ND & ND & 0.047 & Cl8:Ic* & 42.88 & 41.88 & 39.53 \\
\hline CII:0 & ND & 0.067 & 0.092 & $\mathrm{Cl} 8: 2 \mathrm{c}$ & 17.84 & 15.4 & 15.97 \\
\hline $\mathrm{Cl} 3: 0$ & ND & 0.071 & 0.243 & $\mathrm{Cl} 18: 3 \omega 3^{* *}$ & ND & ND & 0.081 \\
\hline $\mathrm{Cl} 4: 0$ & 1.37 & 0.908 & 0.109 & C20:I & ND & $-N D$ & 0.146 \\
\hline $\mathrm{Cl} 6: 0$ & 38.37 & 37.45 & 35.09 & SFAs & 43.69 & 41.98 & 36.121 \\
\hline Cl7:0 & 0.122 & 0.113 & 0.107 & USFAs & 60.72 & 57.43 & 56.28 \\
\hline Cl8:0 & 3.83 & 3.31 & 2.78 & SFAs: USFAs & 이:01.5 & 이:01.4 & 01:01.3 \\
\hline
\end{tabular}

$25 \%$ eggplant puree and $75 \%$ eggplant puree from butter in chocolate spread.

$* \mathrm{C}$ is isomerism,

**omega- 3 fatty acids, SFAs saturated fatty acids and USFAs unsaturated fatty acids.

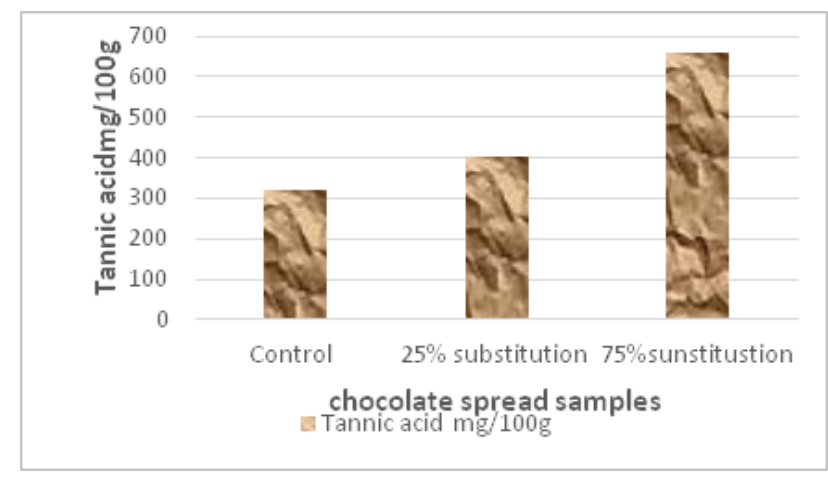

Figure 2 Tannic acid content $\mathrm{mg} / \mathrm{l} 00 \mathrm{~g}$ in samples of chocolate spread.

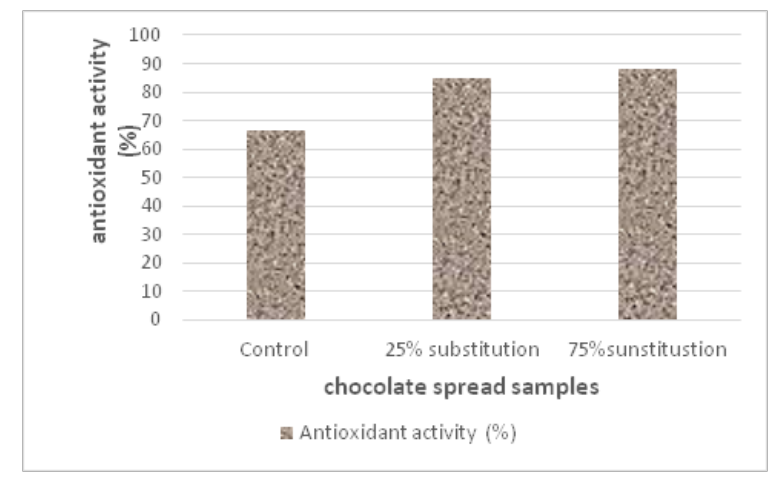

Figure 3 Antioxidant activity (\%) in samples of chocolate spread. 


\section{Storage stability}

Results in (Table 6) showed that the different parameters for estimating the quality of prepared chocolate spread formulas in comparison between the formula which was made with animals butter and the other two formulas with $25 \%$ and $75 \%$ eggplant puree as partial fat replacer. Firstly, free fatty acids were 4.31, 5.74 and $10.57 \%$ in the control, $25 \%$ eggplant puree and $75 \%$ eggplant puree formulas, respectively after three months of storage. And these values were increased with the increasing of the percent of eggplant puree in the formula $25 \%$ and $75 \%$ to near to the double referring to increasing the amount of moisture and increasing the water activity in formula $75 \%$ eggplant puree and occurring hydrolysis of the fat and liberation of some fatty acids. Secondly, the values of thiobarbituric acid were
6.0, 6.33 and $6.87 \mathrm{mg}$ Malonaldehde/ $\mathrm{kg}$ in control, $25 \%$ and $75 \%$ samples, respectively. Finally, the total count and yeasts and molds was not detected in the control formula but they were detected in the two eggplant puree and there were significant differences between the both. The count of total bacteria were 14.33 and $97.00 \mathrm{log} \mathrm{cfu} / \mathrm{g}$ for $25 \%$ and $75 \%$ formulas, respectively. On the other hand, molds and yeasts were less than $10 \mathrm{cfu} / \mathrm{g}$ after 3 months of cold storage in $25 \%$ formulas while were more than $30 \mathrm{cfu} / \mathrm{g}$ in $75 \%$ formulas. Patange et al. ${ }^{43}$ stated that FFA increased in low fat ghee-based spreads with and without potassium sorbate as preservative during storage at $5{ }^{\circ} \mathrm{C}$ and packaged in $200 \mathrm{~g}$ polystyrene tubs and the rate of increase was higher in the product without the preservative where in free fatty acids increased from initial 24.0 to $32.8 \mu$ equiv/g after 5 weeks of storage.

Table 6 Storage stability as free fatty acids (\%), thiobarbituric acid (TBA as mg malon aldehyde / $\mathrm{kg}$ ), Microbiological evaluation as total count and yeasts and molds ((log cfu/g) of chocolate spread formulas (\%)

\begin{tabular}{|c|c|c|c|c|c|c|c|}
\hline \multirow{3}{*}{ Components } & \multicolumn{7}{|l|}{ Formulas } \\
\hline & \multicolumn{2}{|c|}{ Control (100\%butter) } & \multicolumn{2}{|c|}{$25 \%$ substitution } & \multicolumn{3}{|c|}{$75 \%$ substitution } \\
\hline & Zero time & After 3 months & Zero time & After 3 months & Zero time & After 3 months & LSD \\
\hline Free Fatty acids (\%,as oleic acid) & $1.73 \pm 0.22^{c}$ & $4.31 \pm 0.42^{b}$ & $2.58 \pm 0.24^{b}$ & $5.74 \pm 0.63^{b}$ & $4.51 \pm 0.15^{a}$ & $10.57 \pm 0.42^{\mathrm{a}}$ & 1.59 \\
\hline TBA (mg Malon-aldehyde/kg) & $2.21 \pm 0.18^{b}$ & $6.00 \pm 2.50^{c}$ & $2.81 \pm 0.13^{a}$ & $6.33 \pm 0.00^{\mathrm{b}}$ & $2.88 \pm 0.1 \mathrm{I}^{\mathrm{a}}$ & $6.87 \pm 0.0 \mathrm{I}^{\mathrm{a}}$ & 0.04 \\
\hline \multicolumn{8}{|l|}{ Microbiological evaluation } \\
\hline Total bacterial count (log cfu/g) & ND* & ND* & ND* & $14.33 \pm 3.06^{\mathrm{b}}$ & ND* & $97.00 \pm 22.00^{\mathrm{a}}$ & 25.62 \\
\hline Yeasts \& moulds (log cfu/g) & ND* & ND* & ND* & $<10$ & ND* & $<30$ & - \\
\hline
\end{tabular}

Each value of each formula is a mean of three replicates \pm SD. Means followed by the same letter, in each row are not significantly different (ANOVA, LSD test $\mathrm{p} \leq$ 0.05.)

The rate of increase in FFA was much lower in product with potassium sorbate than the product without it, the value increasing from initial 23.6 to $29.4 \mu$ equiv/g after 11 weeks of storage. On the other hand, the initial TBA numbers of the chocolate spread without and with added $0.05 \%(\mathrm{w} / \mathrm{w})$ preservative potassium sorbate at $5^{\circ} \mathrm{C}$ products had 1.25 and $1.27 \mathrm{mg}$ Malon aldehyde $/ \mathrm{kg}$, respectively, which increased to 1.55 and $1.62 \mathrm{mg}$ Malon aldehyde $/ \mathrm{kg}$ at the end of the respective storage periods of 5 and 11 weeks at $5{ }^{\circ} \mathrm{C}$. Further, the TBA value remained almost unchanged during the first 2 weeks of storage in both the spreads, but tended to increase later. We noticed the FFA and TBA values in experimental samples in this paper were relatively high due to the high moisture content in the ingredient especially the eggplant puree.

The microbiological acceptable standards for chocolate confectionary according to FDA (2013) was $1000 \mathrm{cfu} / \mathrm{g}$ and 10 $\mathrm{cfu} / \mathrm{g}$ for yeast and molds. In ghee-based low fat spread, there was a significant increase in the total viable count (TVC) of control spread (from 2.1 to 3.0 to $48 \log \mathrm{cfu} / \mathrm{g}$ ) as well as in the preservative added spread (from 2.1 to $3.2 \mathrm{log} / \mathrm{g}$ ) between 0 to 5 weeks of storage. Between 6 and 9 weeks of storage, the increase in TVC continued up to $4.4 \mathrm{log} / \mathrm{g}$ in the spread with preservative. However, during the last two weeks of storage the count increased only slightly (from 4.6 to 4.7 $\log \mathrm{cfu} / \mathrm{g}$ ). It was thus apparent that the preservative had little effect on TVC. The increase in the TVC with progressive storage indicated that the product with a substantial initial bacterial load provided a fairly good medium for the growth of the organisms.

These results of the current study are in agreement with those found by Amevor et al., ${ }^{44}$ who stated that The microbial load of the chocolate spread samples was within acceptable standards for chocolate candy according to $\mathrm{FDA}^{45}$. As well as TPC were ranged from 250 to $350 \mathrm{cfu} / \mathrm{g}$ which was lower than $1000 \mathrm{cfu} / \mathrm{g}$ reported in the FDA standards. Yeast and mold for the Samples were also less than 10 $\mathrm{cfu} / \mathrm{g}$. Microorganisms such as bacteria, mould and yeast multiply at a high water activity and since most confectionery products have a very low water activity $(<0.75)$, they are stable against microbial spoilage and could be said to be ambient-stable products. ${ }^{46}$ The considerably low levels of TPC and yeast and moulds of samples are indicative of proper handling of raw materials used and satisfactory processing conditions which yielded high hygienic quality of samples. ${ }^{47}$

\section{Conclusion}

The present study was made three formulas of chocolate spread which target to minimize the ratio of fat in such product and compare two low fat formulas with third one which had a full fat ratio, the minimize of fat was by partial replacing with $25 \%$ and $75 \%$ eggplant puree from the total ratio of fat . These replacements were good for healthy food to improve the physical and mental health of people and prevent food diseases.

\section{Funding}

None.

\section{Acknowledgments}

None.

\section{Conflicts of interest}

The authors declare that there was no conflict of interest. 


\section{References}

1. Reis FS, A Martins, MH Vasconcelos, et al. Functional foods based on extracts or compounds derived from mushrooms. Trends in Food Sci Technol. 2017;66:48-62.)

2. Vaclavic CA, EW Christian. Essentials of food science .springer science business media, LLC ,Philadelphia, USA.

3. FAO. Fats and fatty acids in human nutrition :report of an expert consultation, 10-14 november, Geneva, Switzerland; 2008.

4. Hayek SA, SA Ibrahim. Consumeracceptability of chocolate chip cookies using apple sauce as a fat (butter) substitute. Emir J Food Agric. 2013;25(3):159-168.

5. Daubert CR, JF Steffe, AK Srivastava, et al. Predicting theelectro rheological behavior of milk chocolate. J Food Process Eng. 1998;21: 249-261.

6. Rado caj O, E Dimic, LL Diosady, et al.Optimizing the texture attributes of a fat-based spread usinginstrumental measurements. $J$ Texture Studies. 2011;42(5):394-403.

7. Jeyarani T, T Banerjee, R Ravi, et al. Omega-3 fatty acids enriched chocolate spreads using soybeanand coconut oils. J Food Sci. Technol. 2015;52(2):1082-1088.

8. Ognean CF, N Darie, M Ognean. Fat Replacers: review. J Agroalmentary Process and Technol. 2006;12(2):433-442.

9. Ansari A, A Asghar, A Shehzad, et al. Rheological Properties of Papaya Enriched Wheat Flour for Baked Products. Pak J Food Sci. 2014;24(3):126-131.

10. Barber LI, NJT Emelike, BN Sunday. Utilization of Breadfruit in Low Fat Cookie Formulation. J Food Nutri Res. 2016;4(10)1;658-663.

11. Wiese TD, MW Duffrin. Effects of substituting pawpaw fruit puree for fat on thesensory properties of a plain shortened cake. Horttechnology. 2003;13:442-444.

12. Wekwete B, KP Navder. Effects of avocado fruit puree and Oatrim as fat replacerson the physical, textural and sensory properties of oatmeal cookies. J Food Quality. 2008;31:131-141.

13. Martínez-Cervera S, de la Hera E, Sanz T, et al. Effect of nutriose on rheological, textural and sensorial characteristics of Spanish muffins. Food and bioprocess technology. 2012;6(8):1990-1999.

14. Kaur C, S Nagal, J Nishad, et al. Evaluating eggplant (Solanummelongena $L)$ genotypes for bioactive properties: A chemometric approach. Food Res Int. 2014;60:205-211.

15. Jung EJ, MS Bae, EK Jo, et al. Antioxidant activity of different parts of eggplant. J Med Plants Res. 2011;5(18):4610-4615.

16. Garc IA, PG Salas, AM Omez-Caravaca, et al. Identification and quantification of phenolic compounds in diverse cultivars of eggplant grown in different seasons by high-performance liquid chromate graphy coupled to diode array detector and electrospray-quadrupoletime of flight-mass spectrometry. Food Res Int. 2014;57:114-122.

17. Mohamed AE, MN Rashed, A Mofty. Assessment of essential and toxic elements in some kinds of vegetables. Ecotox Environ Safe. 2003;55(3):251-260.

18. Raigón MD, J Prohens, JE Muñoz-Falcón, et al. Comparison of eggplant landraces and commercial varieties for fruit content of phenolics, minerals, dry matter and protein. J Food Compos Anal. 2008;21(5):370376.

19. United States Department of Agriculture (USDA). USDA National Nutrient Database for Standard Reference.

20. Esmaillzadeh A, M Kimiagar, Y Mehrabi, et al. Fruit and vegetable intakes, C-reactive protein, and the metabolic syndrome. Am J Clin Nutr. 2006;84(6):1489-1497.
21. D Kritchevsky, Tepper SA, Story JA. Influence of an eggplant (Solanum melongena) preparation on cholesterol metabolism in rats. Exp Pathol. 1975;10(3): 180-183.

22. Fraikue FB, Kumar JP, Amenumey EK. Production of Makuea poo-ung puree for usage in meal preparation. Asian Journal of Management, 2018;9(1):475-478.

23. El-Hadad NNM, Youssef MM, El-Aal MH, et al. Utilisation of red palm olein in formulating functional chocolate spread. Food Chem. 2011;124(1): 285-290.

24. Kramer A, Twigg BA. Quality Control for the Food Industry. The AVI Publishing Company. Inc., Westport, Connecticut, USA.

25. Prasanth Kumar PK, Jeyarani T, Gopala Krishna AG. Physicochemical characteristics of phytonutrient retained red palm olein and butter-fat blends and its utilization for formulating chocolate spread. J Food Sci Technol. 2016;53(7):3060-3072.

26. AOAC. Official Methods of Analysis of the Association of Official Analytical Chemists, 19 ${ }^{\text {th }}$ ed., Arligton, Virginia, USA. 2012.

27. U.S. EPA. Method 200.7: Determination of Metals and Trace Elements in Water and Wastes by Inductively Coupled Plasma-Atomic Emission Spectrometry. Cincinnati, OH, 1994.

28. Radwan SS. Coupling of two dimensional thin layer chromatography with gas chromatography for the quantitative analysis of lipid classes and their constituent fatty acids. J Chromatogr Sci. 1978;16(11):538542 .

29. Durgawale TP, Durgawale PP, Khanwelkar CC. Quantitative estimation of tannins by HPLC. Der Pharm Lett. 2016;8(3):123-126.

30. Brandwilliams W, Cuvelier ME, Berset C. Use of a free radical method to evaluate antioxidant activity. Food Sci Technol Lebensm Wiss Technol. 1995;28(1):25-30.

31. Poonam JY, Pandey P, Garg SK. Biochemical changes during storage of chocolate. Int Res J Biochem Bioinform. 2011;1(10):242-247.

32. Kirk RS, R Sawyer. In: Pearson's Composition and Analysis of Food, 9th edn. Longman singabore publishers Ltd. USA. 1991.

33. ISO, 8443. Horizontal method for the enumeration of microorganismscolony count technique at $30^{\circ} \mathrm{C}$. International Organization for Standardization. USA. 2003.

34. ICMSF. Microorganisms in foods. The International Commission on Microbiological Specifications for Foods. Toronto, Canada. 1978.

35. SAS. SAS Institute Inc. SAS. /ETS 9. 1 User SAS Institute Inc Users Guide. Cary, NC. 2004.

36. Nazir S, Azad ZRAA. Technological and quality parameters of reducedcalorie chocolates: a review.' Nutrafoods. 2018;17:33-40.

37. Hussein HA. Using Vegetable Puree as a Fat Substitute in Cakes. International J nutr food sci. 2016:5(4):284-292.

38. Afoakwa EO, Paterson A, Fowler M. Effects of particle size distribution and composition on rheological properties of dark chocolate. Eur Food Res Technol. 2008;226( 6):1259-1268.

39. Full NA. Reddy SY, Dimick PS, et al. Physical and sensory properties of milk chocolate formulated with anhydrous milk fat fractions. J Food Sci. 1996;61(5):1068-1084.

40. Adubofuor J, Amoafo Mensah M, Dabri S. Nutritional and physicochemical properties of partially dried ripe pawpaw pulp and assessing the physical properties of rock buns and cakes prepared from the pawpaw pulp incorporated into wheat flour. Afr J Food Sci Technol. 2012;3(10):244-251.

41. Kara HH, Çağlar A, Mercan E, et al. Fatty acid profile and quality specifications of chocolate spreads. Archiv für lebensmittelhygiene, $14 ; 65(2): 40-44$. 
42. Stommel JR, Whitaker BD. Phenolic acid content and composition of eggplant fruit in a germplasm core subset. J Amer Soc Hort Sci. 2003;128(5):704-710.

43. Patange DD, Patel AA, Singh RRB, et al. Storage related changes in ghee- based low-fat spread. J Food Sci Technol. 2013;50(2):346-352.

44. Amevor PM, Laryea D, Barimah J. Sensory evaluation, nutrient composition and microbial load of cashew nut-chocolate spread. Cogent Food \& Agriculture. 2018;4(1):1480180.
45. FDA. Food and Drug Administration. Revised guidelines for the assessment of microbiological quality of processed food (pp.4) Phillipines: Department of Health, Republic of the Philippines, Issue 10. 2013.

46. Subramaniam PJ. Confectionary products. Boca Raton, FL: Leatherhead Food Research Association, CRC Press. pp.221 -246. 2000.

47. Marriot NG. Essentials of food sanitation. Chapman and Hall. USA. 1997. 